\title{
To your excellent career
}

\begin{abstract}
In this issue, we offer a draft community standard for a postdoctoral career workshop that can be used as a template and resource for career development at any institution. This document addresses the issue of what can be standardized to improve the lot of postdoctoral researchers, given that this is a professional group with diverse objectives that is motivated mainly by scientific curiosity.
\end{abstract}

\section{L} ast year, we organized a workshop together with Karolinska Institutet's Junior Faculty, who are research staff with a doctoral degree but no permanent appointment. From this event, they came up with a core curriculum to enable their peers to organize Excellent Career Workshops at other institutions in a similar format (see p. 118, Table 1). Since in many countries there is little or no organized provision for postdoctoral career advice and mentoring, the peer workshop, augmented by input from senior researchers and funders, is helpful and appreciated.

Future workshops will need to incorporate professional training. Some types of professional advisors are indeed available-for example, scientific writing consultants from our sister company Macmillan Science Communication (http://www.mscediting.com/ other-services/training.html) and recruitment services, such as NatureJobs (http://www.nature.com/naturejobs/), as well as independent career advice services, such as the UK Careers Research and Advisory Centre (http://www.crac.org.uk/). There are also some remaining needs for advice that are less easily met. Where does a researcher find a 'leadership program manager', 'career coach' and 'innovation expert'? Mechanisms are also needed for recruiting independent mentors from among the cohort of senior researchers and matching them with junior researchers.

With the sudden freedom of a postdoctoral appointment comes the realization that you are now responsible for your own career and that it cannot be advanced solely by successfully meeting the research objectives of the laboratory in which you are training. There have now been several surveys that emphasize the fact that many institutes do not yet have an office for postdoctoral and contract researchers. The surveys also highlight common causes of loss of morale and research productivity, including poor management, lack of explicit communication and appraisal, mentorship failure and conflicts (for examples, see the survey from the US Sigma Xi Scientific Research Society, Nat. Genet. 37, 653, 2005 and http://www.nber.org/ sewp/Davis_ SurveyAnalysis20060201.pdf, and the UK Careers in Research
Online Survey 2009, http://www.vitae.ac.uk/CMS/files/upload/ CROS_2009_October.pdf).

Postdoctoral researchers may arrive as high-achieving, idealistic professionals expecting training, inspiration and advancement. So they are unprepared for the reality that they are hired as temporary workers to be directed by principal investigators sometimes lacking appreciable management skills, the latter having been selected by their institutes for their research achievements. It is therefore very encouraging to see new faculty opt to undergo management training while their postdoctoral experiences are still fresh in their minds (Nature 483, 511, 2012).

Research infrastructure and practices are very sensitive to economic incentives in a way that results in an oversupply of postdoctoral positions relative to the market need for researchtrained individuals, particularly in the life sciences (Nature 484, 29-31, 2012). This view may be too narrow and pessimistic if all the career destinations of postdocs are taken into account, and, in our view, the positive recommendations of the UK SET for Success 2002 review (http://tinyurl.com/SirGareth) are still inspirational:

"Recommendation 5.3: a vision for postdoctoral researchers.

It is important for postdoctoral researchers to be able to develop individual career paths, reflecting the different career destinations-Industrial, Academic and Research Associateopen to them, and that funding arrangements reflect the development of these career paths."

This review recommended that institutes take responsibility for postdocs' career plans as a condition of UK government research funding and set aside 2 weeks a year for training.

We think most postdocs and their labs would find such an interruption to precious research time intolerable, and, because a career path is by its nature individual, we and our Junior Faculty partners sought a shorter route to awareness of sources of career help based on personal initiative: hence, the idea for a peer workshop. It's not the only solution, but it serves as the heads-up that postdocs need at some point in their excellent careers. 